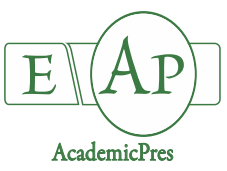

Chalbi A et al. (2021)

Notulae Botanicae Horti Agrobotanici Cluj-Napoca

Volume 49, Issue 3, Article number 12446

DOI: $10.15835 /$ nbha 49312446

Research Article

\title{
Comparative study of the effect of salt stress, Alternaria alternata attack or combined stress on the Cakile maritima growth and physiological performance
}

\author{
Arbia CHALBI ${ }^{1,2 a}$, Besma SGHAIER-HAMMAMI ${ }^{1,3,4 b *}$, \\ Narjes BAAZAOUI ${ }^{5}$, Sofiene B.M. HAMMAMI ${ }^{3}$, \\ Hatem BEN-JOUIRA ${ }^{1}$, Pedro GARCÍA-CAPARRÓS ${ }^{6}$, \\ Naceur DJÉBALI ${ }^{7}$, Imed REGAYA ${ }^{1,8}$, Ahmed DEBEZ ${ }^{1}$, \\ Jesús V. JORRÍN-NOVO ${ }^{4}$, Chedly ABDELLY ${ }^{1}$

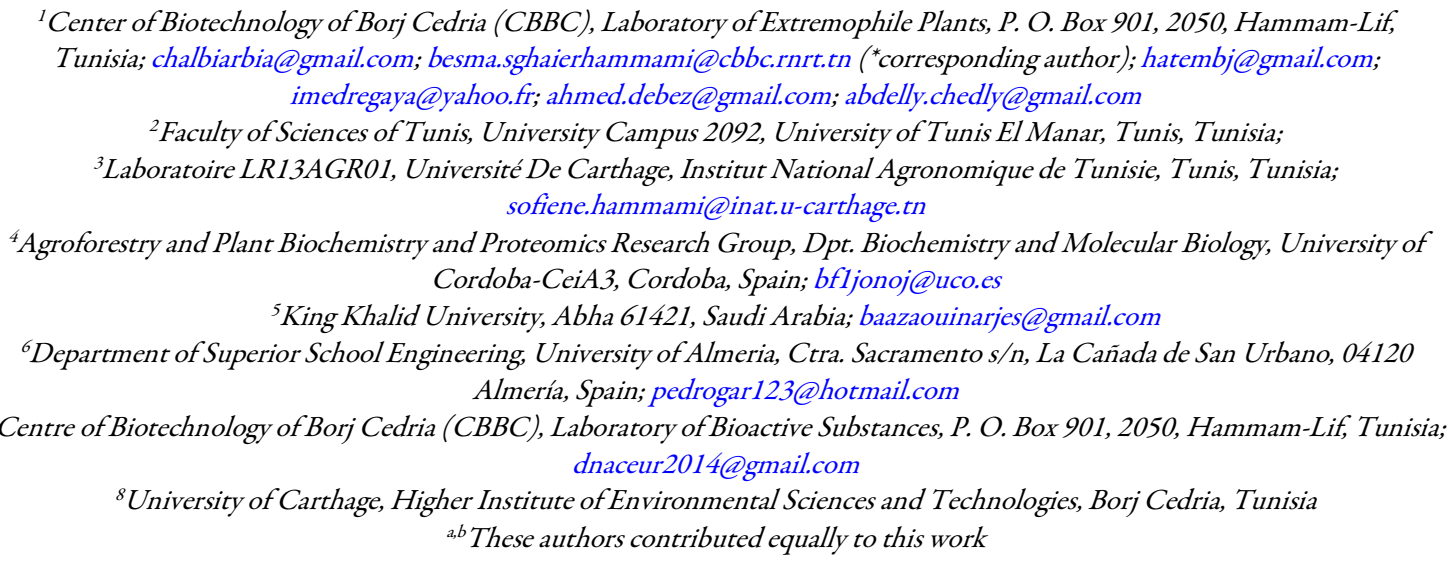

\section{Abstract}

Cakile maritima is a halophytic plant model that is well known by its ability to tolerate high salt concentrations. Salinity was reported to improve the tolerance of halophytes to several abiotic stresses; however, the involvement of salt in the tolerance to biotic stress is still scant. In the present work, the effect of salt on $C$. maritima responses towards the pathogenic Alternaria alternata was investigated. For that, $C$. maritima seeds were germinated for four weeks. Plants were then divided into four groups: i) Plants irrigated with salt (200mM NaCl); ii) Plants infested by fungus; iii) Plants irrigated with salt and infested by fungus and finally control plants $(0 \mathrm{mM} \mathrm{NaCl}$, without inoculation). Our results showed that upon salt stress or fungal attack, plants reduced biomass production, hydration status and photosynthetic performance which were associated with a decrease in the gas exchange and chlorophyll fluorescence parameters, with a more pronounced effect upon fungal attack. However, under combined stress, a significant increase of these parameters was noticed, with a level close to that of control. Concerning nutrient contents, $\mathrm{K}, \mathrm{Zn}, \mathrm{Fe}, \mathrm{Cu}$ and $\mathrm{Mg}$ decreased in the $C$. maritima leaves exposed to both stresses applied individually. In contrast, all these nutrients were increased in plants grown under combined stress. Taken together, we can conclude that plants 
grown under combined stresses had better growth rate and physiological performance compared to all other treated plants, and that salt may be the key in improving the C. maritima ability to tolerate fungal attack.

Keywords: Alternaria alternata; Cakile maritima; combined stress; fungal attack alleviation; salt stress

Abbreviations: FW: fresh weight; DW: dry weight; A: net $\mathrm{CO}_{2}$ assimilation rate; gs: stomatal conductance; E: transpiration rate; $\mathrm{Ci}$ : internal $\mathrm{CO}_{2}$ concentration; WUE: Water use efficiency; MDA: malondialdehyde; D: dissipation of excess photon energy in the PSII antenna; NPQ: non-photochemical quenching; Fv/Fm: the maximum quantum efficiency of photosystem II photochemistry; $\mathrm{q}_{\mathrm{p}}$ : photochemical quenching

\section{Introduction}

Cakile maritima (family: Brassicaceae) commonly known as sea rocket, is an obligate halophyte frequently found in littoral sandy dunes along the Mediterranean seashore, acting as soil stabilizer (Flowers and Colmer, 2008, 2015). This halophyte is considered as oilseed ( $40 \%$ oil on seed dry weight basis) (Zarrouk et al., 2003) and it has been eaten traditionally as an antiscorbutic, diuretic and purgative and its leaves were used for salads, amongst other culinary uses (Davy et al., 2006).

C. maritima has a small size genome $(1 \mathrm{C}=719 \mathrm{Mb})$ and a short life cycle, and recently is considered as model system for halophytes to address salt stress tolerance mechanisms (Arbelet-Bonnin et al., 2019; Debez et al., 2013). Besides being necessary to its growth, salinity (salt stress) was reported to exhibit beneficial effects on their tolerance to abiotic stress (Hamed et al., 2013). In literature, several studies have investigated saltenhanced tolerance to other abiotic stresses in halophyte plants. For instance, in Hordeum maritimum, phosphorus deficiency was alleviated following the application of moderate salinity (Zribi et al., 2012). Similarly, Glenn et al. (2012) reported that salinity improves Atriplexspp. tolerance to water deficiency (Glenn et al., 2012). Furthermore, beneficial salt effects on Sesuvium portula castrum responses to drought stress (Slama et al., 2007) and heavy metals (Ghnaya et al., 2005) were also reported.

The adaptation of halophytes to abiotic stress after an exposition to salt stress could be due to either cross-tolerance, anticipation or stress memory (Hamed et al., 2013). In C. maritima, a proposed mechanism was due to the development of a relatively long-term stress memory in plants pre-exposed to salinity which resulted in a lower oxidative stress when subsequently exposed to others abiotic stresses or salt stress (Ellouzi et al., 2013). In addition, the co-existence of salinity with other stresses leads to the amplification of certain physiological and biochemical tolerance traits commonly associated with salinity such as the accumulation of osmolyte, $\mathrm{K}: \mathrm{Na}$ selectivity, $\mathrm{Na}^{+}$exclusion and vacuolar compartmentalization, antioxidant capacity (enzyme and antioxidant molecules) (Gil et al., 2011; Shiri et al., 2015; Hassan et al., 2017). Moreover, the adaptation of halophyte plants involves a variety of protective mechanisms that stabilize photosystems, preserve the photosynthetic apparatus, secure the Calvin cycle enzymes, and control the redox state of many components (Ben Amor et al., 2020; Farhat et al., 2021).

Overall, these investigations indicate that salt has a beneficial effect on halophytes adaptation to abiotic stress. However, in their habitats, halophytes were exposed to multiple stresses among them the biotic factors. Hence, here it is important to know if salt has the same role on the response of halophytes to biotic stress. In fact, in their habitat, C. maritima are colonized by several fungal strains of Alternaria (Chalbi et al., 2020), with Alternaria alternata being the most pathogenic. Indeed, it affects the adequate development of the crops and also leads to a reduction of post-harvest quality (Akimitsu et al., 2014; Meena and Samal, 2019; Somma et al., 2019). Despite the identification of different pathogenic strains of Alternaria from the different organs (seeds, stem and leaves) of $C$. maritima, it is worth noting that plants spontaneously grown on saline habitats seem to be less affected by Alternaria than those cultivated under laboratory experiments conditions (Chalbi et al., 2020). Since salinity is the most important factor in the halophyte habitat, we may postulate that its presence 
may confer some degree of tolerance to biotic stress. Thus, the objective of the present work was to study the effect of salt stress or $A$. alternata attack applied separately, or in combination, on the physiological performance of $C$. maritima plants. Thus, the investigation of salt involvement on the mitigation of fungal attack should be the focus of future studies that aim at developing transgenic crops tolerating naturally occurring environmental conditions.

\section{Materials and Methods}

\section{Fungal material}

Alternaria alternata was isolated from C. maritima plants and identified by (Chalbiet al., 2020) as Alternaria alternata strain (ITEM17830). Conidial suspensions were prepared from 2-week-old cultures by adding $10 \mathrm{~mL}$ of distilled water to each plate and rubbing the surface of each culture with a spreader bar. Conidial suspensions were adjusted to $10^{6}$ conidia $\mathrm{mL}^{-1}$ following hemocytometer counts.

\section{Plant culture and treatments}

C. maritima seeds were collected from coastal dunes in Djerba, an island in Southeast of Tunisia characterized by temperate winters $\left(10{ }^{\circ} \mathrm{C}\right.$ and $17{ }^{\circ} \mathrm{C}$ represented the minimal and maximal average temperatures, respectively) and annual rainfall of $100-200 \mathrm{~mm}$ (arid region). For salt treatment, we have used $200 \mathrm{mM} \mathrm{NaCl}$ as was reported previously by our group to induce salt stress (Farhat et al., 2021; Ben Amor et al., 2020; Megdiche et al., 2007). Seeds were sown in pots of $0.5 \mathrm{~L}$ (four seeds per pot) filled with inert sand and daily watered with tap water until germination. The experiment was performed in a growth room under controlled conditions: 16 - $\mathrm{h}$ light/ 8 -h dark photoperiod; $25 \pm 1{ }^{\circ} \mathrm{C}$ temperature; $60 \pm 2 \%$ relative humidity and $440 \mu \mathrm{molm}^{-2} \mathrm{~s}^{-1}$ photosynthetic active radiations (PAR). Plants were then daily watered with $100 \mathrm{~mL}$ of Hewitt nutrient solution ( $\mathrm{pH} 7.3$, EC $2.7 \mathrm{mS} \mathrm{cm}^{-1}$ ) (Hewitt and Eden, 1953) for four weeks. Twenty-eight-day-old plants were partitioned into two lots, which were grown under salt-free conditions and salt conditions (200 $\mathrm{mM}$ of $\mathrm{NaCl}$ ) for two weeks. Then, the different lots of plants previously reported were separated into two groups: the first one was sprayed with $20 \mathrm{~mL}$ of $\mathrm{H}_{2} \mathrm{O}$ (non-inoculated plants) in leaves; whereas for the second one leaves were sprayed with $20 \mathrm{~mL} \mathrm{H}_{2} \mathrm{O}$ of a conidial suspension at a concentration of $10^{6} \mathrm{CFU} \mathrm{mL} \mathrm{m}^{-1}$ of $A$. alternata until run-off (inoculated plants). Each group was covered with transparent plastic bags to keep an atmosphere saturated with humidity to promote infection, and then they were placed in the dark for 48 hours at $25^{\circ} \mathrm{C}$. The experimental design consisted of two treatments (Figure 1), four blocks, and five plants per block (one plant per pot, supplementary Figure 1).

\section{Plant infection assessment}

To assess the inoculation process of $A$. alternata on $C$. maritima leaves, inoculated and non-inoculated leaf samples were twice properly washed with distilled water. The monitoring of the infection process begins from 2 to 96 hours post inoculation (hpi). The Section crosswise was then cut into transparent slices with the help of a sterilized blade or scalpel. Thin cross sections of leaf samples were decolorized with $0.15 \%(\mathrm{w} / \mathrm{v})$ TCA in ethanol: chloroform (3:1) and then wet mounted with a drop of $0.01 \%$ lactophenol cotton blue on a glass slide and covered with a cover slip. Slides were observed under light microscope (Zeiss AX10 Star Plus) at 50$60 \mathrm{~Hz}$ and $65 \mathrm{~V}$. More than fifty samples were examined to confirm the results. Conidia numbers were counted by image analysis methods. 


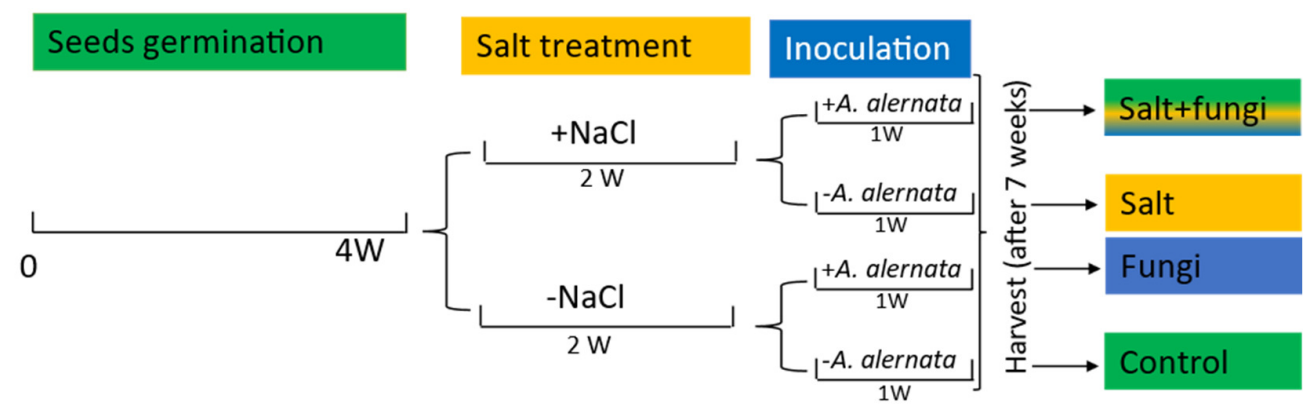

Figure 1. Schematic overview of the experimental design, Salt + fungi; infested plants with $A$. alternate and grown under salt, Salt; plants grown under salt stress, fungi; plants infested by the fungi, Control; plants grown under $0 \mathrm{mM} \mathrm{NaCl}$ without inoculation, W: week

\section{Biomass parameters and water status}

Leaf fresh weight (FW) and dry weight (DW) were determined at the end of the experiment (after 7 weeks). DW was obtained after oven-drying the leaves at $60{ }^{\circ} \mathrm{C}$ for $72 \mathrm{~h}$. Measurement of the water content (WC) was determined according to the following formulate: [(FW - DW)/DW].

\section{Gas exchange measurements}

The determination of leaf gas exchange parameters was conducted using an infrared gas analyzer $(\mathrm{LCi}$ portable photosynthesis system, ADC BioScientific Ltd., Hoddesdon, Herts, UK). The following parameters were recorded at saturating light: net $\mathrm{CO}_{2}$ assimilation rate $(\mathrm{A})$, stomatal conductance (gs), transpiration rate (E) and internal $\mathrm{CO}_{2}$ concentration $(\mathrm{Ci})$. All the parameters were measured at a photosynthetic available radiation of $800 \mu \mathrm{mol} \mathrm{m} \mathrm{m}^{-2} \mathrm{~s}^{-1}$ (saturated light intensity), $65 \pm 5 \%$ relative humidity, $28 \pm 2{ }^{\circ} \mathrm{C}$ leaf temperature and $350 \mu \mathrm{mol} \mathrm{mol}^{-1} \mathrm{CO}_{2}$ concentration. The water use efficiency (WUE) was estimated using the following formula: $\mathrm{WUE}=\mathrm{A} / \mathrm{E}$ (Christophe et al., 2018). All measurements were performed between 09:30 am and 10:30 am in fully expanded leaves (the same leaf stage from the bottom). Values of the above-mentioned parameters were taken after the stabilization of the photosynthetic levels.

\section{Chlorophyll fluorescence determinations}

The chlorophyll fluorescence measurements were made using a fluorometer type DUAL-PAM-100 (Walz, Germany) on the upper surface of the intact plants, five replicates were performed, one leaf (from the middle) from each plant. The minimum fluorescence $\left(\mathrm{F}_{0}\right)$ was determined one hour after the adaptation of leaves to dark that were then light saturated to determine the maximum fluorescence $\left(\mathrm{F}_{\mathrm{m}}\right)$ and the maximum quantum efficiency of photosystem II photochemistry $\left(F_{v} / F_{m}\right)=\left(F_{m}-F_{0}\right) / F_{m}$. Non-photochemical quenching of fluorescence (NPQ) was determined with the equation $\left(F_{m}-F_{m}{ }^{\prime}\right) / F_{m}$ '. Photochemical quenching of fluorescence $\left(\mathrm{q}_{\mathrm{p}}\right)$ was determined using the equation $\left(\mathrm{F}_{\mathrm{m}}{ }^{\prime}-\mathrm{F}_{\mathrm{s}}\right) /\left(\mathrm{F}_{\mathrm{m}}{ }^{\prime}-\mathrm{F}_{0}{ }^{\prime}\right)$. The determination of the intrinsic efficiency of open photosystem II ( $\Phi$ exc) was calculated as the ratio between $\mathrm{F}_{\mathrm{v}}{ }^{\prime} / \mathrm{F}_{\mathrm{m}}{ }^{\prime}$. The actual photosystem II efficiency was calculated as $F_{q}{ }^{\prime} / F_{m}{ }^{\prime}=\left(F_{m}{ }^{\prime}-F_{s}\right) / F_{m}$. The efficiency of dissipation of excess photon energy in the photosystem II antenna (D) was determined using the equation $1-\Phi$ exc $=1-\left(F_{v}{ }^{\prime} / F_{m}{ }^{\prime}\right)$. All these equations were reported by (Schreiber and Ulrich, 2004).

\section{Leaf macronutrients and micronutrients concentrations}

Oven-dried leaves were ground into a fine powder using a mortar. About $0.3 \mathrm{~g}$ of dried leaves were digested with $0.5 \%$ of nitric acid $\left(\mathrm{HNO}_{3}\right)$ at room temperature for four days. Then, the extracts were filtered and used for the determination of nutrient concentration. Chloride was assessed by colorimetry (Büchler), K and $\mathrm{Na}$ by flame spectrophotometry (Corning, United Kingdom), and Mg and micronutrients concentration by atomic absorption spectrophotometry (Perkin Elmer 4000). 


\section{Lipid membrane peroxidation}

Lipid peroxidation was measured to assess the oxidative stress induced membrane damage by determining malondialdehyde (MDA) content, using the thiobarbituric acid method according to (Draper and Hadley, 1990). Fresh leaf samples (the third leaf from the top) were homogenized in $0.1 \%$ (w/v) TCA solution and centrifuged at $15,000 \mathrm{~g}$ for $10 \mathrm{~min}$. An aliquot of the supernatant was added to $0.5 \%$ TBA in $20 \%$ TCA and the mixture was heated at $95^{\circ} \mathrm{C}$ for $30 \mathrm{~min}$ in a shaking water bath. After cooling in an ice bath and subsequent centrifugation $\left(10,000 \mathrm{~g}\right.$ for $10 \mathrm{~min}$ at $\left.4{ }^{\circ} \mathrm{C}\right)$, the supernatant absorbance at $532 \mathrm{~nm}$ was read and values corresponding to nonspecific absorption $(600 \mathrm{~nm})$ were subtracted. MDA content was calculated according to the molar extinction coefficient of MDA $\left(155 \mathrm{mM}^{-1} \mathrm{~cm}^{-1}\right)$.

\section{Statistical analysis}

Data were presented as mean \pm SEM of five replicates. Statistical analyses were performed using the Statistix 8.0 software. For multiple group comparisons ANOVAs followed by Student'st-test were used. For all analyses $\mathrm{p}<0.05$ was considered significant. For PCA and cluster analysis of all the parameters measured, the web-based software NIA array analysis tool (Sharovet al., 2005) available at http://lgsun.grc.nia.nih.gov/anova/index.html was used. This software tool selects statistically valid parameters value based on analysis of variance (ANOVA). The entire data set was analyzed by principal component analysis (PCA) using the following settings: covariance matrix type, four principal components, two-fold change threshold for clusters, and 0.5 correlation threshold for clusters. PCA results were represented as a biplot, with different treatments used in those experimental situations located on the same area of the graph.

\section{Results}

\section{Alternaria leaf infection process}

Conidia of $A$. Alternaria was found to be small and septate with short beak (Figure 2A). Light micrograph (40X) showed that the fungus $A$. alternate penetrated to its host via conidia (Figure 2B, D) or mycelia (Figure 2C, E) throughout the stomata (Figure 2B, C) or epidermis (Figure 2D, E). A. alternata infected $C$. maritima leaf tissue revealed damage to cell and cell wall as compared to healthy tissue (Figure $2 \mathrm{~F}$ ). The damaged portions were found to be discoloured because of interaction with the fungus and it may be due to production of toxins (Figure $2 \mathrm{G}$ ).

The monitoring of $A$. alternata multiplication on C. maritima leaves was performed via light micrograph observation from 2 to 96 hours post inoculation (hpi) (Figure 3A-F). Results showed an increase from 6 to 49 conidia $/ \mathrm{mm}^{2}$ from 2 to $4 \mathrm{hpi}$. The number of conidia per surface increased nearly by ten-fold, reaching 436 conidia $/ \mathrm{mm}^{2}$ at $18 \mathrm{hpi}$. The maximum rate of fungus colonization in leaves was from $48 \mathrm{hpi}$ to 72 and $96 \mathrm{hpi}$ with values around 5800 conidia $/ \mathrm{mm}^{2}$ (Figure $3 \mathrm{G}$ ).

Based on these data, we have showed, for the first time, the process of penetration of $A$. alternata to $C$. maritima and further results will focus on its impact on the growth and physiology of $C$. maritima plants either grown under salt or salt-free conditions. 


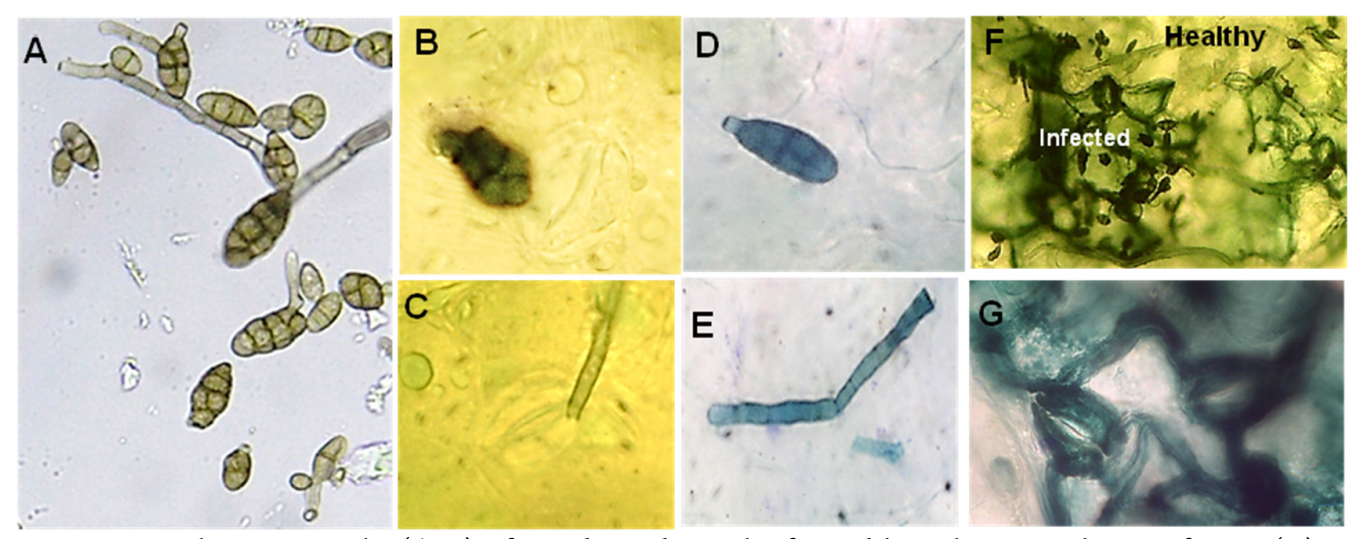

Figure 2. Light micrographs (40X) of conidia and mycelia formed by Alternaria alternate fungus (A), penetration of conidia or mycelia on Cakile maritima leaf throughout the stomata (B, C) or epidermis (D, E), leaf infected tissue showing difference between healthy and infected portion due to Alternaria toxins $(\mathrm{F}, \mathrm{G})$
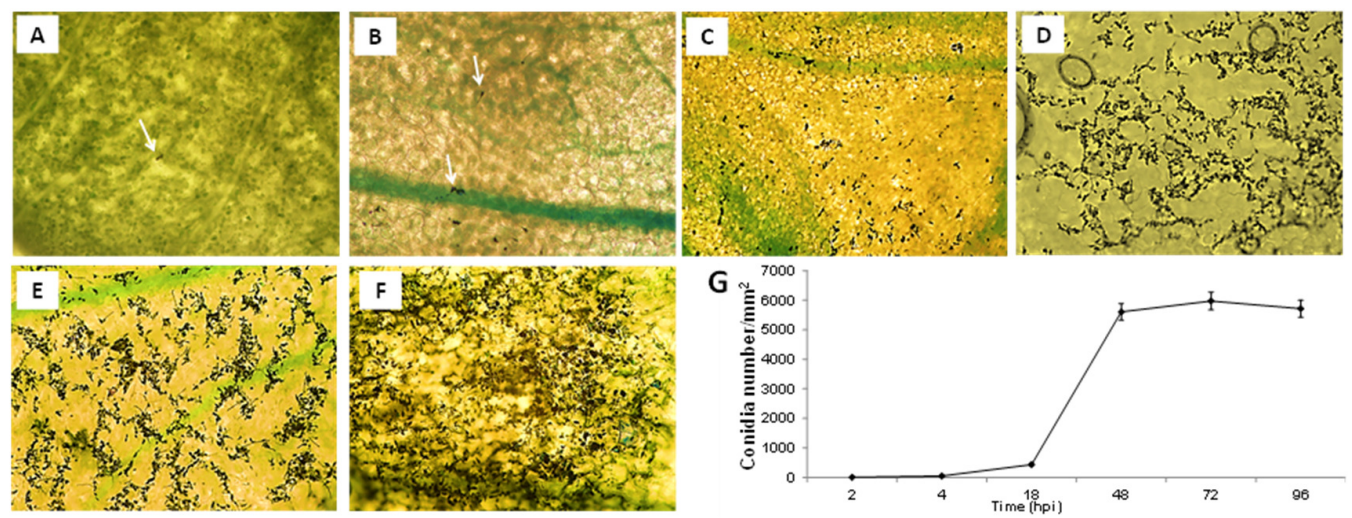

Figure 3. Microscopic observation (40X) of the conidia multiplication at the surface of $C$. maritima leaf upon $A$. alternata inoculation during different hours post inoculation (A;2hpi, B;4hpi, C; 18hpi, D;48hpi, E; 72hpi and F; 96hpi) and the conidia number per $\mathrm{mm}^{2}$ over time (G), hpi: hours post-inoculation, the row indicates the conidia

\section{Assessment of growth parameters under individual or combined stress}

The growth parameters were measured from plants grown either, under salt stress or fungal attack, or under combined stress. Plant biomass was measured as fresh and dry weight (FW, DW). Salt stress or fungal attack significantly impaired growth of $C$. maritima plants compared to controls $(0 \mathrm{mM} \mathrm{NaCl}$ and without inoculation). In fact, FW, DW and water content (WC) decreased when plants were subjected either to 200 $\mathrm{mM} \mathrm{NaCl}$ or $A$. alternata (Figure 3). Plants grown under combined stress exhibited similar parameters values to those of plants grown under salt stress and lesser than control plants (Table 1, Figure 4).

\section{Gas exchange determinations and water use efficiency}

The application of individual stress significantly reduced the photosynthetic gas exchange parameters. For example, the net $\mathrm{CO}_{2}$ assimilation rate (A) decreased by $22 \%$ under salt stress, compared to control plants; however, upon fungal attack, the (A) decreased by $75 \%$. Plants grown under combined stress exhibited similar level of (A) to that of control plants. Similar trends were observed for the transpiration rate (E), stomatal conductance (gs), and water use efficiency (WUE), where the levels of these parameters decreased upon application of individual stress and reached similar and even higher levels to that of control plants under combined stress (Table 2). 


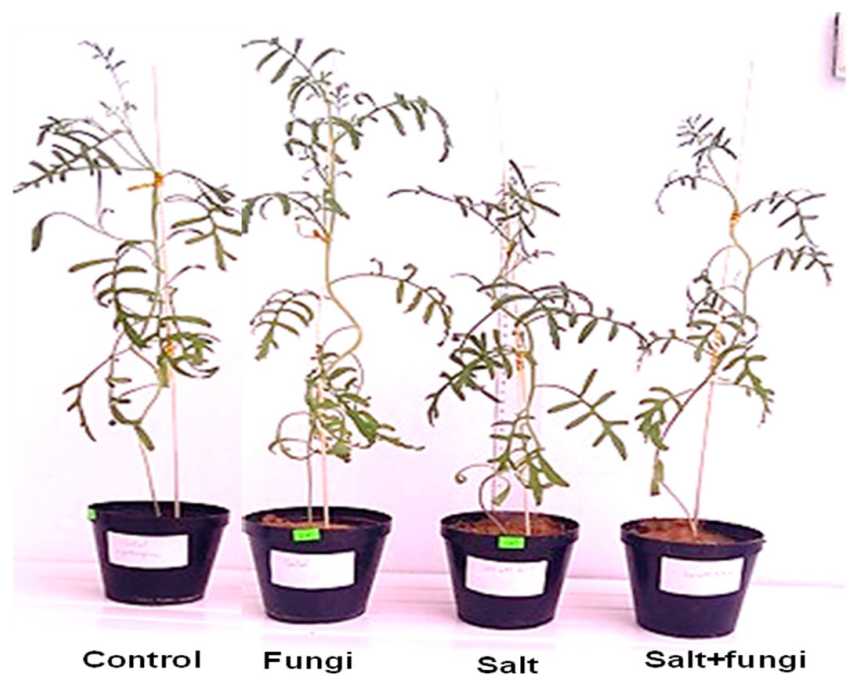

Figure 4. Morphological changes in C. maritima plants under different treatments assessed at the end of the experiment: Control; plants grown under $0 \mathrm{mM} \mathrm{NaCl}$ without inoculation, fungi; plants infested by the fungi, Salt; plants grown under salt stress, Salt + fungi; infested plants with $A$. alternate and grown under salt stress.

Table 1. Effects of different treatments on growth parameters (fresh and dry weight: FW, DW) and water content (WC) of inoculated and non-inoculated $C$. maritima plants with $A$. alternata

\begin{tabular}{|c|c|c|c|}
\hline Parameters & Treatments & SFC & SC \\
\hline FW $(\mathrm{g})$ & Non-inoculated & $6.41 \pm 0.55 \mathrm{aA}$ & $2.49 \pm 0.30 \mathrm{bA}$ \\
\hline & Inoculated & $5.19 \pm 0.58 \mathrm{aB}$ & $2.51 \pm 0.29 \mathrm{bA}$ \\
\hline $\mathrm{DW}(\mathrm{g})$ & Non-inoculated & $0.34 \pm 0.03 \mathrm{aA}$ & $0.20 \pm 0.02 \mathrm{bA}$ \\
\hline & Inoculated & $0.30 \pm 0.03 \mathrm{aB}$ & $0.19 \pm 0.02 \mathrm{bA}$ \\
\hline WC $(\mathrm{g} / \mathrm{DW})$ & Non-inoculated & $17.80 \pm 0.03 \mathrm{aA}$ & $12.47 \pm 0.63 \mathrm{bA}$ \\
\hline & Inoculated & $16.32 \pm 0.03 \mathrm{aB}$ & $11.50 \pm 0.83 \mathrm{bA}$ \\
\hline
\end{tabular}

Values represent means \pm standard error of five plants per treatment. Means within a row with the same lowercase letter are not significantly different at $p<0.05$ (Student's t-test). Means within a column with the same capital letter are not significantly different at $p<0.05$ (Student's t-test), SFC; salt-free conditions, SC; salt conditions.

Table. 2. Effects of different treatments on gas exchange measurements (net $\mathrm{CO}_{2}$ assimilation rate (A), transpiration rate $(\mathrm{E})$, internal $\mathrm{CO}_{2}$ concentration $(\mathrm{Ci})$, stomatal conductance $(\mathrm{gs})$, and water use efficiency (WUE) in non-inoculated and inoculated plants of $C$. maritima with $A$. alternata at the end of the experiment

\begin{tabular}{|l|c|c|c|}
\hline \multicolumn{1}{|c|}{ Parameters } & Treatments & SFC & SC \\
\hline \multirow{2}{*}{$\mathrm{A}\left(\mu \mathrm{mol} \mathrm{CO} \mathrm{m}^{-2} \mathrm{~s}^{-1}\right)$} & Non-inoculated & $9.3 \pm 0.97 \mathrm{aA}$ & $7.3 \pm 0.14 \mathrm{bB}$ \\
\cline { 2 - 4 } & Inoculated & $2.46 \pm 0.70 \mathrm{bB}$ & $8.95 \pm 0.68 \mathrm{aA}$ \\
\hline \multirow{2}{*}{$\mathrm{E}\left(\mathrm{mmol} \mathrm{H} \mathrm{O} \mathrm{m}^{-2} \mathrm{~s}^{-1}\right)$} & Non-inoculated & $1.33 \pm 0.11 \mathrm{aA}$ & $1.05 \pm 0.10 \mathrm{bA}$ \\
\cline { 2 - 4 } & Inoculated & $0.83 \pm 0.12 \mathrm{bB}$ & $1.28 \pm 0.05 \mathrm{aA}$ \\
\hline \multirow{2}{*}{$\mathrm{gs}\left(\mathrm{mmol} \cdot \mathrm{m}^{-2} \mathrm{~s}^{-1}\right)$} & Non-inoculated & $0.086 \pm 0.01 \mathrm{aA}$ & $0.06 \pm 0.01 \mathrm{bA}$ \\
\hline \multirow{2}{*}{$\mathrm{Ci}\left(\mu \mathrm{mol}^{-2} \mathrm{~m}^{-1}\right)$} & Inoculated & $0.036 \pm 0.01 \mathrm{aB}$ & $0.05 \pm 0.01 \mathrm{aA}$ \\
\hline \multirow{2}{*}{$\begin{array}{l}\text { WUE }\left(\mu \mathrm{mol} \mathrm{CO}_{2}\right. \\
\mathrm{mmol}\end{array}$} & Non-inoculated & $252.67 \pm 21.47 \mathrm{aA}$ & $253.67 \pm 17.29 \mathrm{aB}$ \\
\cline { 2 - 4 } & Inoculated & $314.81 \pm 29.94 \mathrm{bA}$ & $361.52 \pm 32.98 \mathrm{aA}$ \\
\cline { 2 - 4 } & Non-inoculated & $8.26 \pm 0.80 \mathrm{aA}$ & $6.43 \pm 0.71 \mathrm{bA}$ \\
\hline
\end{tabular}

Values represent means \pm standard error of five plants per treatment. Means within a row with the same lowercase letter are not significantly different at $p<0.05$ (Student's t-test). Means within a column with the same capital letter are not significantly different at $p<0.05$ (Student's t-test), SFC; salt-free conditions, SC; salt conditions. 


\section{Chlorophyll fluorescence determinations}

Under salt stress, the following fluorescence parameters: the maximal quantum yield of fluorescence $(\mathrm{Fv} / \mathrm{fm})$, quantum yield of PSII electron transport (ФPSII) and intrinsic efficiency of open photosystem II (Фexc) exhibited similar levels compared to control plants. However, the non-photochemical quenching (NPQ), photochemical quenching $\left(\mathrm{q}_{\mathrm{p}}\right)$ and the efficiency of dissipation of excess photon energy in the PSII antenna (D) decreased compared to control plants. Under $A$. alternata attack, Fv/Fm, NPQ, $\mathrm{q}_{\mathrm{p}}$ and D were significantly reduced by $5,26,8$, and $50 \%$, respectively. However, under combined stress, plants showed an increase in the following parameters: $\mathrm{Fv} / \mathrm{Fm}, \mathrm{NPQ}, \mathrm{q}_{\mathrm{p}}$ and $\mathrm{D}$, compared to plants grown under salt conditions (Table 3). Besides, some of the parameters $\left(\mathrm{Fv} / \mathrm{Fm}, \mathrm{q}_{\mathrm{p}}\right)$ were close to those of control plants.

Table 3. Effects of different treatments on maximum quantum efficiency of PSII $\left(\mathrm{F}_{\mathrm{v}} / \mathrm{F}_{\mathrm{m}}\right)$, nonphotochemical quenching (NPQ), photochemical quenching $\left(\mathrm{q}_{\mathrm{p}}\right)$, quantum yield of PSII electron transport (ФPSII), intrinsic efficiency of open photosystem II (Фexc) and efficiency of dissipation of excess photon energy in the PSII antenna (D) in Cakile maritima at the end of the experiment

\begin{tabular}{|c|c|c|c|}
\hline Parameters & Treatments & SFC & SC \\
\hline \multirow{2}{*}{$\mathrm{Fv} / \mathrm{Fm}$} & Non-inoculated & $0.75 \pm 0.01 \mathrm{aA}$ & $0.77 \pm 0.06 \mathrm{aA}$ \\
\hline & Inoculated & $0.63 \pm 0.04 \mathrm{bB}$ & $0.74 \pm 0.03 \mathrm{aA}$ \\
\hline \multirow{2}{*}{ NPQ } & Non-inoculated & $1.71 \pm 0.11 \mathrm{aA}$ & $0.14 \pm 0.14 \mathrm{bB}$ \\
\hline & Inoculated & $0.45 \pm 0.02 \mathrm{bB}$ & $0.66 \pm 0.04 \mathrm{aA}$ \\
\hline \multirow{2}{*}{$\mathrm{q}_{\mathrm{p}}$} & Non-inoculated & $1.66 \pm 0.26 \mathrm{aA}$ & $1.28 \pm 0.27 \mathrm{bB}$ \\
\hline & Inoculated & $1.38 \pm 0.23 \mathrm{bB}$ & $1.76 \pm 0.29 \mathrm{aA}$ \\
\hline \multirow{2}{*}{ ФPSII } & Non-inoculated & $0.65 \pm 0.06 \mathrm{aA}$ & $0.71 \pm 0.06 \mathrm{aA}$ \\
\hline & Inoculated & $0.73 \pm 0.07 \mathrm{aA}$ & $0.67 \pm 0.06 \mathrm{aA}$ \\
\hline \multirow{2}{*}{ Фexc } & Non-inoculated & $0.56 \pm 0.03 \mathrm{aA}$ & $0.58 \pm 0.04 \mathrm{aA}$ \\
\hline & Inoculated & $0.54 \pm 0.04 \mathrm{aA}$ & $0.53 \pm 0.03 \mathrm{aA}$ \\
\hline \multirow{2}{*}{$\mathrm{D}$} & Non-inoculated & $0.97 \pm 0.07 \mathrm{aA}$ & $0.32 \pm 0.05 \mathrm{bB}$ \\
\hline & Inoculated & $0.49 \pm 0.01 \mathrm{bB}$ & $0.58 \pm 0.06 \mathrm{aA}$ \\
\hline
\end{tabular}

Values represent means \pm standard error of five plants per treatment. Means within a row with the same lowercase letter are not significantly different at $p<0.05$ (Student's t-test). Means within a column with the same capital letter are not significantly different at $p<0.05$ (Student's t-test), SFC; salt-free conditions, SC; salt conditions.

\section{MDA contents}

The MDA content increased significantly by $20 \%$ in plants grown under salt stress and by $50 \%$ in infested plants, compared to control plants. Under combined conditions, the MDA content was similar to those plants grown under salt stress conditions and lesser than that of infested plants grown under salt free condition but remained higher compared to control plants (Table 4).

Table 4. Membrane lipid peroxidation determination (MDA). Values represent means \pm standard error of five plants per treatment

\begin{tabular}{|c|c|c|c|}
\hline Parameters & Treatments & SFC & SC \\
\hline \multirow{2}{*}{ MDA (nmol g-1 FW) } & Non-inoculated & $3.74 \pm 0.19 \mathrm{bB}$ & $5.24 \pm 0.66 \mathrm{aA}$ \\
\cline { 2 - 4 } & Inoculated & $7.07 \pm 0.13 \mathrm{aA}$ & $6.0 \pm 0.59 \mathrm{bA}$ \\
\hline
\end{tabular}

Values represent means \pm standard error of five plants per treatment. Means within a row with the same lowercase letter are not significantly different at $p<0.05$ (Student's t-test). Means within a column with the same capital letter are not significantly different at $p<0.05$ (Student's t-test), SFC; salt-free conditions, SC; salt conditions.

\section{Leaf macronutrient concentrations}

Under salt stress, an increase in sodium and a decrease in potassium concentrations in C. maritimaleaves was recorded compared to control plants. Upon inoculation, the $\mathrm{K}^{+}$concentration decreased but that of $\mathrm{Na}^{+}$ remained unchanged compared to control plants. Under combined conditions, $\mathrm{Na}^{+}$and $\mathrm{K}^{+}$concentrations 
showed levels that are similar to that of plants grown under salt stress. Concerning leaf $\mathrm{Mg}$ concentration, it decreased either under salt stress or upon fungal attack; while, under combined stress, plants showed the highest Mg level compared to all other treatments (Table 5).

Table 5. Effects of different treatments on macronutrients concentrations in Cakile maritima at the end of the experiment

\begin{tabular}{|c|c|c|c|}
\hline Parameters & Treatments & SFC & SC \\
\hline \multirow{2}{*}{$\mathrm{K}^{+}\left(\mathrm{mmol} \mathrm{g}^{-1} \mathrm{DW}\right)$} & Non-inoculated & $61.95 \pm 5.83 \mathrm{aA}$ & $45.53 \pm 4.31 \mathrm{bA}$ \\
\cline { 2 - 4 } & Inoculated & $57.92 \pm 1.02 \mathrm{aB}$ & $46.68 \pm 4.01 \mathrm{bA}$ \\
\hline \multirow{2}{*}{$\mathrm{Na}^{+}\left(\mathrm{mmol} \mathrm{g}^{-1} \mathrm{DW}\right)$} & Non-inoculated & $31.16 \pm 3.23 \mathrm{bA}$ & $66.65 \pm 6.16 \mathrm{aA}$ \\
\cline { 2 - 4 } & Inoculated & $31.85 \pm 3.20 \mathrm{bA}$ & $69.59 \pm 6.15 \mathrm{aA}$ \\
\hline \multirow{2}{*}{$\mathrm{Mg}\left(\mathrm{mmol} \mathrm{g}^{-1} \mathrm{DW}\right)$} & Non-inoculated & $1.29 \pm 0.03 \mathrm{aA}$ & $1.05 \pm 0.04 \mathrm{bB}$ \\
\cline { 2 - 4 } & Inoculated & $1.08 \pm 0.10 \mathrm{bB}$ & $1.57 \pm 0.15 \mathrm{aA}$ \\
\hline
\end{tabular}

Values represent means \pm standard error of five plants per treatment. Means within a row with the same lowercase letter are not significantly different at $p<0.05$ (Student's $\mathrm{t}$-test). Means within a column with the same capital letter are not significantly different at $p<0.05$ (Student's t-test), SFC; salt-free conditions, SC; salt conditions.

\section{Leaf micronutrient concentrations}

Leaf $\mathrm{Cu}, \mathrm{Fe}$ and $\mathrm{Zn}$ concentrations were reduced in plants exposed to salt stressor fungal attack, whereas the concentration of $\mathrm{Mn}$ increased compared to control plants. The decrease was more pronounced under fungal attack than salt stress. Under combined conditions, all these micronutrient elements concentrations increased compared to control plants (Table 6).

Table 6. Effect of different treatments on micronutrients concentration in Cakile maritima at the end of the experiment

\begin{tabular}{|c|c|c|c|}
\hline Parameters & Treatments & SFC & SC \\
\hline \multirow{2}{*}{$\mathrm{Cu}\left(\mu \mathrm{mol} \mathrm{g}{ }^{-1} \mathrm{DW}\right)$} & Non-inoculated & $0.86 \pm 0.08 \mathrm{aA}$ & $0.78 \pm 0.07 \mathrm{bA}$ \\
\cline { 2 - 4 } & Inoculated & $0.63 \pm 0.05 \mathrm{bB}$ & $0.93 \pm 0.06 \mathrm{aA}$ \\
\hline \multirow{2}{*}{$\mathrm{Fe}\left(\mu \mathrm{mol} \mathrm{g}{ }^{-1} \mathrm{DW}\right)$} & Non-inoculated & $3.03 \pm 0.36 \mathrm{aA}$ & $2.81 \pm 0.25 \mathrm{aB}$ \\
\cline { 2 - 4 } & Inoculated & $2.35 \pm 0.22 \mathrm{bB}$ & $3.26 \pm 0.23 \mathrm{aA}$ \\
\hline \multirow{2}{*}{$\mathrm{Zn}\left(\mu \mathrm{mol} \mathrm{g}{ }^{-1} \mathrm{DW}\right)$} & Non-inoculated & $1.29 \pm 0.12 \mathrm{aA}$ & $1.05 \pm 0.11 \mathrm{bB}$ \\
\cline { 2 - 4 } & Inoculated & $1.01 \pm 0.10 \mathrm{bB}$ & $1.57 \pm 0.12 \mathrm{aA}$ \\
\hline \multirow{2}{*}{$\mathrm{Mn}\left(\mu \mathrm{mol} \mathrm{g}{ }^{-1} \mathrm{DW}\right)$} & Non-inoculated & $2.19 \pm 0.19 \mathrm{bB}$ & $2.84 \pm 0.26 \mathrm{aA}$ \\
\cline { 2 - 4 } & Inoculated & $2.59 \pm 0.23 \mathrm{bA}$ & $2.93 \pm 0.27 \mathrm{aA}$ \\
\hline
\end{tabular}

Values represent means \pm standard error of five plants per treatment. Means within a row with the same lowercase letter are not significantly different at $p<0.05$ (Student's t-test). Means within a column with the same capital letter are not significantly different at $p<0.05$ (Student's t-test), SFC; salt-free conditions, SC; salt conditions.

\section{Principal component analysis (PCA) and expression cluster}

In order to consolidate our findings, the PCA and cluster analyses were performed by analyzing all the assessed parameters that characterize the response of $C$. maritima to salt stress, fungal attack and combined stress. PC1 and PC2 represented $48.5 \%$ and $24 \%$ of the biological variability, respectively (supplementary Table 1). Based on the PC1, Control plants were separated from the rest of the treatments; however, they were grouped by PC2 with plants grown under salt stress (Salt) and plants grown under combined stress (Combined), that they share somehow similar common behavior. The separation of inoculated plants from all the rest of treatments, confirm our previous findings that fungal attack was shown to be more deleterious than salt stress (Figure 5a). The cluster analysis showed that the control and inoculated plants were very distant. Nevertheless, control plants and those cultivated under combined stress were very close (Figure 5b). Thus, the 
results obtained by PCA and cluster analysis validated our hypothesis that salt can improve the plant tolerance against $A$. alternata attack.
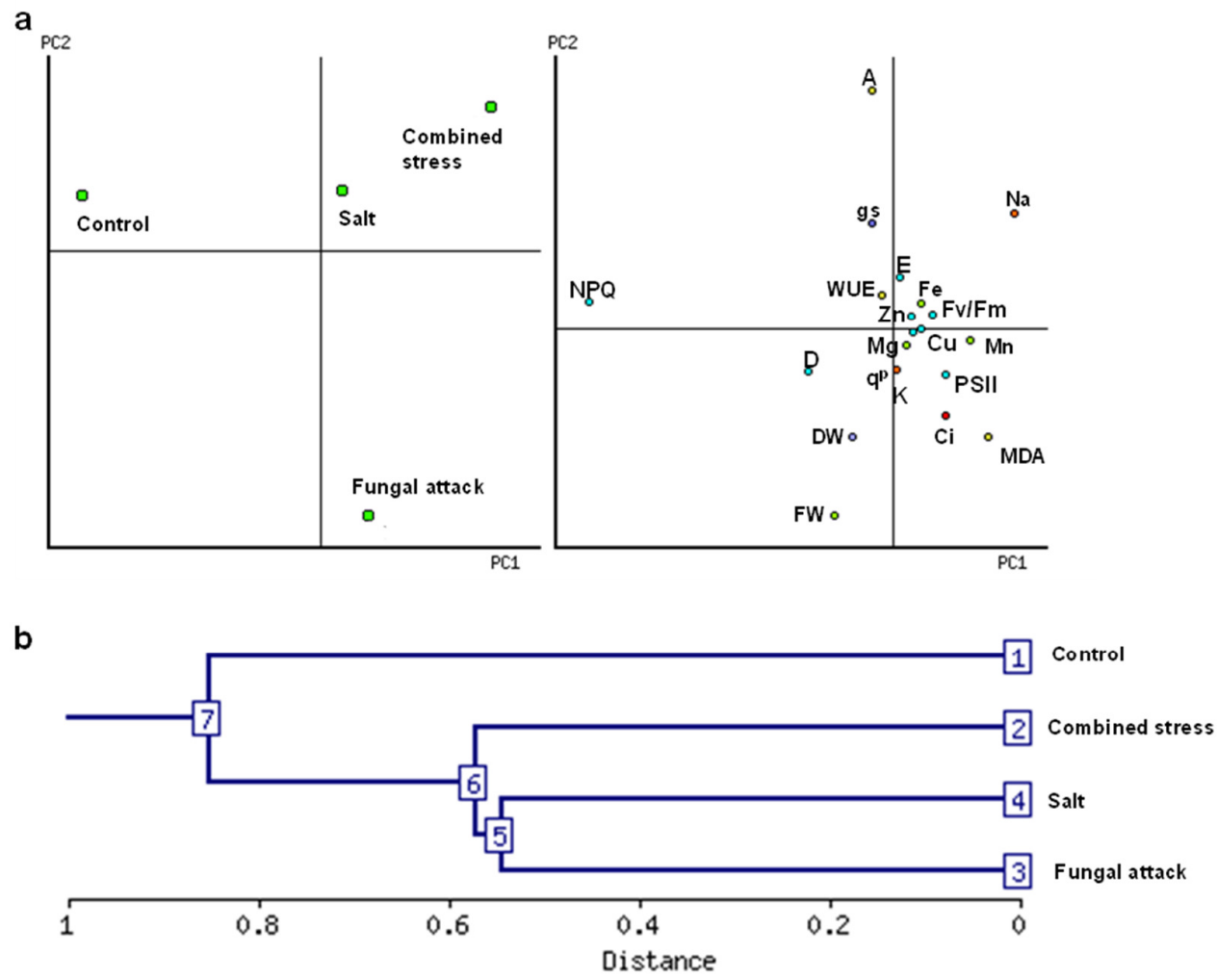

Figure 5. Two-dimensional blots generated by principal component analysis (PCA, a) using all morphophysiological parameters (on the right of the blot) and cluster analysis (b). Control; plants grown on $0 \mathrm{mM} \mathrm{NaCl}$ without inoculation, Salt; plants grown under salt stress, Fungal attack; plants grown under salt-free conditions and infested by $A$. alternata, and combined stress; plants grown under salt conditions and infested by $A$. alternata

\section{Discussion}

\section{Impact of $A$. alternata attack on C. maritima growth and physiological performances}

Recently, we have isolated and identified several strains of Alternaria genus from the halophyte $C$. maritima (Chalbi et al., 2020). However, here for the first time the penetration modes, the multiplication rate and the conidia numbers were reported. The microscopic infection process of $A$. alternata on $C$. maritima was similar to that of infection by wild type $A$. brassicicola on cabbage leaf surface (Scott and Lawrence, 2008). $A$. brassicicola on Cauliflower (Sobczak et al., 2020) and A. brassicae on mustard (Giri et al., 2013; Mamgain and Biswas, 2020). Light microscopy results showed that the germ tube was found to penetrate the leaf cell through stomata or epidermis. The finding is a common feature of this genus, as reported in $A$. porri (Aveling et al., 1994), A. linicola (Vloutoglou et al., 1996), A. alternata (Gupta et al., 1998). Our data showed that the cells in the substomatal area were necrotic and the death may be because of diffusible toxins (Sinha et al., 2014; Chalbi et al., 2020). In our present work we found that $A$. alternata conidia number increased rapidly over time and reach their maximum at $48 \mathrm{hpi}$ with an increase in necrosis of cells over time. Similarly, the analysis of the impact of $A$. brassicicola on Brassica oleracea leaves showed that the number of germinating conidia increased gradually with the post-inoculation time at $20 \mathrm{hpi}$, indicating fast and massive fungal development on susceptible 
hosts(Sobczak et al., 2020). The number of conidia of $A$. porri infecting onion was similar to the number of $A$. alternata reported in our work (Mohsin et al., 2016).

At physiological level, $A$. alternata altered the plants biomass and water use efficiency (WUE). In addition, $A$. alternata triggered several negative effects on $C$. maritima plants such as stomatal closure and decrease in the net $\mathrm{CO}_{2}$ assimilation. Similarly, it has been reported in Eucalyptus urophylla, that Puccinia psidii infection caused a reduction in stomatal conductance which caused a restriction in photosynthesis process in infected plants by limiting the flow of $\mathrm{CO}_{2}$ in leaf area (Alves et al., 2011; Mohammadi Alagoz et al., 2016). Riberio et al. (2004) showed that in orange seedlings, $\mathrm{CO}_{2}$ assimilation and stomatal conductance (gs) were higher in healthy plants compared to those infected by Xylella fastidiosa (Ribeiro et al., 2004). Polando et al. (2014) also pointed out a similar relationship between plants infected with Colletotrichum lindemuthianum (Polanco et al., 2014).

Besides to damages occurred on the gas exchange parameters, A. Alternaria caused a decrease in the maximum quantum efficiency of PSII $\left(\mathrm{F}_{\mathrm{v}} / \mathrm{F}_{\mathrm{m}}\right)$, indicating that the PSII reaction center was damaged by $A$. alternata, leading to a decline in the overall rate of electron transport $\left(\mathrm{q}_{\mathrm{p}}\right)$. The decrease in fluorescence parameters may be due to Alternaria mycotoxins secreted in the host (Chalbi et al., 2020) which is considered as an energy-transfer inhibitor (such as the tentoxin) (Arntzen, 1972). Similar to our results, Arntzen (1972) reported that the inoculation with Alternaria species caused an inhibition of photosynthetic electron transport (Arntzen, 1972) and consequently leading to over reduction of the photosystem II (Sobczak et al., 2020). The decrease in photosynthetic efficiency could be a result of the fungus-induced necrotic lesion expansion (Sobczak et al., 2020). The necrotic lesions in leaves induce an increase in the lipid peroxidation (MDA) which is an indicator of membrane integrity damage and is a considerable marker of oxidative stress (Møller and Hansson, 2007). Lipids were shown to be modulated upon inoculation with the tolerant grapevine Vitis vinifera cv. Regent with $P$. viticola, particularly at 6 and $12 \mathrm{hpi}$, which decreased when compared to mockinoculated samples (Cavaco et al., 2021). Altogether, the present findings confirm the damages caused by the A. alternata fungus on C. Maritima growth and physiology, and the possibility of the involvement of salt in the mitigation of the effect of fungal attack will be discussed in the next section.

\section{Salt involvement in the alleviation of the attack of Altenraria alternata in Cakile maritima}

Despite the attack with the pathogen, the growth of $C$. maritima under salt condition led to a positive effect on gas exchange parameters (increase in the net $\mathrm{CO}_{2}$ assimilation rate, transpiration rate and stomatal conductance) and water use efficiency, compared to those grown under salt-conditions. The water use efficiency was shown to be a good tool for measuring the ability of a plant to adjust its gas exchange parameters under stressful conditions by increasing $\mathrm{CO}_{2}$ capture and reducing water losses (Gleick et al., 2011). Likewise, the adverse effects of $A$. alternata on the photosynthetic performance of $C$. maritima were reduced when plants were grown under salt stress. In fact, the maximum quantum efficiency of PSII (Fv/Fm) in infested $C$. maritima, grown under salt conditions, remained similar to control plants despite fungal attack. Indeed, it showed normal PSII reaction center functioning which helped in keeping normal levels of PSII photochemical activity and photosynthetic electron transport (Yang et al., 2018). In parallel, an increase in the level of photochemical quenching $\left(\mathrm{q}_{\mathrm{p}}\right)$, the efficiency of dissipation of excess photon energy in the PSII antenna (D) and the non-photochemical quenching (NPQ), compared to infected plant, were observed. This increase in photosynthetic parameters suggested that the dissipation of excess energy may have played a protective role in the photosynthetic apparatus in plants challenged with stress facing the excess of photo energy (Qiu et al., 2003; Wided et al., 2009).

For non-halophytic plants, the presence of salt and other biotic stresses has effects that are more adverse. For example, in cucumber the synergetic effect of salt and pathogen resulted in a stronger decrease in photosynthetic parameters (Chojak-Koźniewska et al., 2018). Similarly, in A. thaliana, the photosynthetic parameters were more adversely affected by the synergetic effect of salt stress and pathogen compared to when both stresses applied separately (Demirbas and Acar, 2017). In our case, the mitigation effect of salt stress on 
the pathogen attack might be related to the fact that this is a halophyte plant and thus may induce the stress memory phenomena by the enhancement of the abundance of protective proteins involved in photosynthesis activation and protein biosynthesis (Hamed et al., 2013; Shiri et al., 2015). The formation of a stress memory happens when the plant keeps a 'stress imprint' following the exposure to a stress that improves the plant's response to recurrent stress compared to plants without that stress memory (Ellouzi et al., 2013). This suggests that after the exposure to a first stress, plants use a set of defense mechanisms using elements that could persist for several weeks after relief from a first stress. This allows stress pre-exposed plants either to prevent and/or scavenge reactive oxygen species more efficiently than non-pre-exposed plants. Slama et al. (2007b) showed that when the halophyte Sesuvium portula castrum was exposed to salinity followed by water deficit, photosynthesis machinery and water status were improved (Slama et al., 2007). Similarly, Ellouzi et al. (2013) reported the beneficial effect of pre-exposure to high salinity and Cd stress in improving the resistance to high salinity (Ellouzi et al., 2013).

There is a strong relationship between photosynthesis activity and MDA content (Álvarez and SánchezBlanco, 2015). In the present work, the level of MDA decreased after dual application of salt-stress and pathogen attack despite the increase following the application of both stresses separately. Similarly, it has been shown previously that the concentrations of MDA reached maximum values at $24 \mathrm{~h}$ following salt stress then decreased later on in C. maritima when exposed to second abiotic stress (Ellouzi et al., 2013). Our data also showed that there was a close link between the decrease in MDA content and the increase in PSI and PSII function. Similar data was reported by Xu et al. $(2009,2011)$ where it was shown that lipid peroxidation is closely associated with photosynthesis and PSII activities (Xu et al., 2009, 2011). This may suggest that plants were protected from oxidative damage under combined stress that is why they exhibited better functioning.

Concerning nutrient uptakes, the present results showed that salt stress or fungal attack positively impacted the uptake of $\mathrm{Mn}$, but decreased that of $\mathrm{K}, \mathrm{Fe}, \mathrm{Zn}, \mathrm{Cu}$ and $\mathrm{Mg}$ in C. maritima leaves. In contrast, the $\mathrm{Mg}, \mathrm{Cu}, \mathrm{Zn}, \mathrm{Mn}$ and Fe concentrations have increased in inoculated seedlings by $A$. alternata, grown under salt stress (combined stress). In fact, $\mathrm{Mg}$ as a component of chlorophyll, $\mathrm{Fe}$ as a component of ferridoxin and cytochromes; $\mathrm{Zn}$ as a component of glutamic, alcohol and lactic dehydrogenase, and carbonic anhydrase; $\mathrm{Cu}$ as a component of laccase, cytochrome oxidase, ascorbic acid oxidase, and polyphenol oxidase; and $\mathrm{Mn}$ as a component of arginase and phosphotransferase, may be mobilized and utilized by plants and may be influenced by the adverse or favorable environmental growth conditions (Manzoor Alam, 1999; Sogoni et al., 2021). The improvement in the absorption of $\mathrm{Mg}$ and $\mathrm{Fe}$ can contribute to the maintenance of energy transfer integrity and protein synthesis. In fact, this micronutrient plays an important role in the production of chlorophyll (20 to $25 \%$ of the total magnesium of the plant is located in the chloroplasts). Hence, this prevents the ions from interfering with the pathways of growth and metabolism and the reduction of negative impacts of salinity combined to fungal attack (Evelin et al., 2009).

\section{Conclusions}

To conclude, in the present work, salt stress negatively affected $C$. maritima growth, water status, mineral nutrition, photosynthesis activity, nutrient uptakes and MDA concentrations. Similar and more pronounced negative effects were obtained when plants were inoculated by $A$. alternata. In the presence of salt conditions, inoculated halophyte plants exhibited better physiological performance than inoculated plants grown under salt-free conditions and even better than those non-inoculated (control). This ability to mitigate fungal attack can be related to the presence of salt in the medium culture of plants, and to the genetic patrimony of halophytes. Molecular investigations are required to unravel this exciting relationship between salt and biotic stress in halophyte which remained until now poorly understood. 


\section{Authors' Contributions}

Conceptualization: AC and NJ; Data curation: HBJ and IR; Formal analysis: SBMH and HBJ; Funding acquisition: BSH; Methodology: AC and NJ; Supervision: BSH and CA; Validation: BSH and JJN; Writing original draft: $\mathrm{BSH}$ and PGC; review and editing: NB, JJN, SBMH, IR, AD. All authors read and approved the final manuscript.

\section{Acknowledgements}

Please rewrite the acknowledgements as bellow: The authors extend their appreciation to the Deanship of Scientific Research at King Khalid University for funding this work through the Small Research Project under grant number (R.G.P.1/195/41). Also, the authors would like to thank the Tunisian Ministry of Higher Education, Scientific Research and Technology (LR19CBBC02), for funding this project under grant number 19PEJC07-17

\section{Conflict of Interests}

The authors declare that there are no conflicts of interest related to this article.

\section{References}

Akimitsu K, Tsuge T, Kodama M, Yamamoto M, Otani H (2014). Alternaria host-selective toxins: Determinant factors of plant disease. Journal of General Plant Pathology 80(2):109-122. https://doi.org/10.1007/s10327-013-04987

Álvarez S, Sánchez-Blanco MJ (2015). Comparison of individual and combined effects of salinity and deficit irrigation on physiological, nutritional and ornamental aspects of tolerance in Callistemon laevis plants. Journal of Plant Physiology 1(185):65-74 https://doi.org/10.1016/j.jplph.2015.07.009

Alves AA, Guimarães LM da S, Chaves AR de M, DaMatta FM, Alfenas AC (2011). Leaf gas exchange and chlorophyll a fluorescence of Eucalyptus urophylla in response to Puccinia psidii infection. Acta Physiologiae Plantarum 33(5):1831-1839. https://doi.org/10.1007/s11738-011-0722-z

Arbelet-Bonnin D, Ben-Hamed-Louati I, Laurenti P, Abdelly C, Ben-Hamed K, Bouteau F (2019). Cakile maritima, a promising model for halophyte studies and a putative cash crop for saline agriculture. Advances in Agronomy 155:45-78. https://doi.org/10.1016/bs.agron.2019.01.003

Arntzen CJ (1972). Inhibition of photophosphorylation by tentoxin, a cyclic tetrapeptide. BBA - Bioenergetics 283(3):539-542. https://doi.org/10.1016/0005-2728(72)90273-3

Aveling TAS, Snyman HG, Rijkenberg FHJ (1994). Morphology of infection of onion leaves by Alternaria porri. Canadian Journal of Botany 72(8):1164-1170. https://doi.org/10.1139/b94-142

Ben Amor N, Jiménez A, Boudabbous M, Sevilla F, Abdelly C (2020). Chloroplast implication in the tolerance to salinity of the halophyte Cakile maritima. Russian Journal of Plant Physiology 67(3):507-514. https://doi.org/10.1134/S1021443720030048

Cavaco AR, Matos AR, Figueiredo A (2021). Speaking the language of lipids: the cross-talk between plants and pathogens in defence and disease. Cellular and Molecular Life Sciences 78(9):4399-4415. https://doi.org/10.1007/s00018021-03791-0

Chalbi A, Sghaier-hammami B, Meca G (2020). Characterization of mycotoxigenic Alternaria species isolated from the Tunisian halophyte Cakile maritima. Phytopathologia Mediterranea 59(1):107-118. https://doi.org/10.14601/Phyto-10720

Chojak-Koźniewska J, Kuźniak E Zimny J (2018). The effects of combined abiotic and pathogen stress in plants: insights from salinity and Pseudomonas syringaepv lachrymans interaction in cucumber. Frontiers in Plant Science 9:1691. https://doi.org/10.3389/fpls.2018.01691 
Christophe BG, Hermann P, Séraphin AZ, Agapit DW, Stanley L, David HM, Françoise AK, Armel CGM (2018). Effects of salinity stress on growth in relation to gas exchanges parameters and water status in amaranth (Amaranthus cruentus). International Journal of Plant Physiology and Biochemistry 10(3):19-27. https://doi.org/10.5897/ijppb2018.0280

Davy AJ, Scott R, Cordazzo CV (2006) Biological flora of the British Isles: Cakile maritima Scop. Journal of Ecology 94:695-711. https://doi.org/10.1111/j.1365-2745.2006.01131.x

Debez A, Rejeb K Ben,Ghars MA, Gandour M, Megdiche W, Hamed K Ben, Amor N Ben, Brown SC, Savouré A, Abdelly C (2013). Ecophysiological and genomic analysis of salt tolerance of Cakile maritima. Environmental and Experimental Botany 92:64-72. https://doi.org/10.1016/j.envexpbot.2012.12.002

Demirbas S, Acar O (2017). Physiological and biochemical defense reactions of Arabidopsis thaliana to phelipanche ramosa infection and salt stress. Fresenius Environmental Bulletin 26(3):2268-2275.

Draper HH, Hadley M (1990). Malondialdehyde determination as index of lipid peroxidation. Methods in Enzymology 186(C):421-431. https://doi.org/10.1016/0076-6879(90)86135-I

Ellouzi H, Ben Hamed K, Asensi-Fabado MA, Müller M, Abdelly C, Munné-Bosch S (2013). Drought and cadmium may be as effective as salinity in conferring subsequent salt stress tolerance in Cakile maritima. Planta 237(5):13111323. https://doi.org/10.1007/s00425-013-1847-7

Evelin H, Kapoor Rand Giri B (2009). Arbuscular mycorrhizal fungi in alleviation of salt stress: A review. Annals of Botany 104(7):1263-1280. https://doi.org/10.1093/aob/mcp251

Farhat N, Kouas W, Braun H-P, Debez A (2021). Stability of thylakoid protein complexes and preserving photosynthetic efficiency are crucial for the successful recovery of the halophyte Cakile maritima to high salinity. Plant Physiology and Biochemistry 166:177-190. https://doi.org/10.1016/j.plaphy.2021.05.044

Flowers TJ, Colmer TD (2008). Salinity tolerance in halophytes. New Phytologist 179(4):945-963. https://doi.org/10.1111/j.1469-8137.2008.02531.x

Flowers TJ, Colmer TD (2015). Plant salt tolerance: Adaptations in halophytes. Annals of Botany 115(3):327-331. https://doi.org/10.1093/aob/mcu267

Ghnaya T, Nouairi I, Slama I, Messedi D, Grignon C, Abdelly C, Ghorbel MH (2005). Cadmium effects on growth and mineral nutrition of two halophytes: Sesuvium portulacastrum and Mesembryanthemum crystallinum. Journal of Plant Physiology 162(10):1133-1140. https://doi.org/10.1016/j.jplph.2004.11.011

Gil R, Lull C, BoscaiuM, Bautista I, Lidón A, Vicente O (2011). Soluble carbohydrates as osmolytes in several halophytes from a Mediterranean salt marsh. Notulae Botanicae Horti Agrobotanici Cluj-Napoca 39(2):9-17. https://doi.org/10.15835/nbha3927176

Giri P, Taj G, Meena P D, Kumar A, Pradesh U (2013). Microscopic study of Alternaria brassicae infection processes in Brassica juncea cultivars by drop plus agarose method. African Journal of Microbiology Research 7(33):4284-4290. https://doi.org/10.5897/AJMR2013.5585

Gleick P H, Christian-Smith J, Cooley H (2011). Water-use efficiency and productivity: Rethinking the basin approach. Water International 36(7):784-798. https://doi.org/10.1080/02508060.2011.631873

Glenn EP, Nelson SG, Ambrose B, MartinezR, Soliz D, Pabendinskas V, Hultine K (2012). Comparison of salinity tolerance of three Atriplex spp. in well-watered and drying soils. Environmental and Experimental Botany 82:6272. https://doi.org/10.1016/j.envexpbot.2012.04.010

Gupta VP, Raju HV, Kumar V, Govindaiah (1998). Surface ultrastructure of infection process of Alternaria alternata and Fusarium pallidoroseum on mulberry. Archives of Phytopathology and Plant Protection 31(5):429-434. https://doi.org/10.1080/03235409809383254

Hamed K Ben, Ellouzi H, Talbi O Z, Hessini K, Slama I, Ghnaya T, Bosch SM, Savouré A, Abdelly C (2013). Physiological response of halophytes to multiple stresses. Functional Plant Biology 40(9):883-896. https://doi.org/10.1071/FP13074

Hassan M Al, Chaura J, Donat-Torres MP, Boscaiu M, Vicente O (2017). Antioxidant responses under salinity and drought in three closely related wild monocots with different ecological optima. AoB PLANTS 9:plx009. https://doi.org/10.1093/aobpla/plx009

Hewitt EJ, Eden A (1953). Sand and water culture methods used in the study of plant nutrition. The Analyst 78(926):329-330. https://doi.org/10.2136/sssaj1966.03615995003000040002x

Mamgain A, Biswas MK (2020). Impact of different environmental factors on the progression of Alternaria blight of mustard caused by Alternaria brassicae. Alochana Chakra Journal IX(V):6843-6859. 
Manzoor Alam S (1999). Nutrient uptake by plants under stress conditions. Handbook of Plant and Crop Stress 2:285313. https://doi.org/10.1201/9780824746728.ch12

Meena M, Samal S (2019). Alternaria host-specific (HSTs) toxins: An overview of chemical characterization, target sites, regulation and their toxic effects. Toxicology Reports 6:745-758. https://doi.org/10.1016/j.toxrep.2019.06.021

Megdiche W, Amor N Ben, Debez A, Hessini K, Ksouri R, Zuily-Fodil Y, Abdelly C (2007). Salt tolerance of the annual halophyte Cakile maritima as affected by the provenance and the developmental stage. Acta Physiologiae Plantarum 29(4):375-384. https://doi.org/10.1007/s11738-007-0047-0

Mohammadi Alagoz S, Toorchi M, Bandehagh A (2016). Canola seedling response to $\mathrm{NaCl}$ stress - a proteomic approach. Notulae Botanicae Horti Agrobotanici Cluj-Napoca 44(2):361-366. https://doi.org/10.15835/nbha44210462

Mohsin SM, Islam MR, Ahmmed ANF, Nisha HAC, Hasanuzzaman M (2016). Cultural, morphological and pathogenic characterization of alternaria porri causing purple blotch of onion. Notulae Botanicae Horti Agrobotanici ClujNapoca 44(1):222-227. https://doi.org/10.15835/nbha44110110

Møller IM, Jensen PE, Hansson A (2007). Oxidative modifications to cellular components in plants. Annual Review of Plant Biology 58:459-481. https://doi.org/10.1146/annurev.arplant.58.032806.103946

Polanco LR, Rodrigues FA, Nascimento KJT, Cruz MFA, Curvelo CRS, DaMatta FM, Vale FXR (2014). Photosynthetic gas exchange and antioxidative system in common bean plants infected by Colletotrichum lindemuthianum and supplied with silicon. Tropical Plant Pathology 39(1):35-42. https://doi.org/10.1590/S198256762014000100005

Qiu N, Lu Q, Lu C (2003). Photosynthesis, photosystem II efficiency and the xanthophyll cycle in the salt-adapted halophyte Atriplex centralasiatica. New Phytologist 159(2):479-486. https://doi.org/10.1046/j.14698137.2003.00825.x

Ribeiro RV, Machado EC, Oliveira RF (2004). Growth- and leaf-temperature effects on photosynthesis of sweet orange seedlings infected with Xylella fastidiosa. Plant Pathology 53(3):334-340. https://doi.org/10.1111/j.00320862.2004.01012.x

Schreiber U, Ulrich S (2004). Pulse-Amplitude-Modulation (PAM) fluorometry and saturation pulse method: an overview. In: Chlorophyll a fluorescence 279-319. https://doi.org/10.1300/j301v01n03_06

Scott DC, Lawrence C (2008). The cell wall integrity-associated map kinase homolog, AbSlt2 in the ecrotrophic fungus Alternaria brassicicola is required for pathogenicity of Brassicas. Masters Theses [20058]. http://hdl.handle.net/10919/31203

Sharov AA, Dudekula DB, Ko MSH (2005). A web-based tool for principal component and significance analysis of microarray data. Bioinformatics 15(10):2548-2549. https://doi.org/10.1093/bioinformatics/bti343

Shiri M, Rabhi M, El Amrani A, Abdelly C (2015). Cross-tolerance to abiotic stresses in halophytes: application for phytoremediation of organic pollutants. Acta Physiologiae Plantarum 37(10). https://doi.org/10.1007/s11738015-1954-0

Sinha M, Singh RP, Kushwaha GS, Iqbal N, Singh A, Kaushik S, Kaur P, Sharma S, Singh TP (2014). Current overview of allergens of plant pathogenesis related protein families. The Scientific World Journal. https://doi.org/10.1155/2014/543195

Slama I, Ghnaya T, Messedi D, Hessini K, Labidi N, Savoure A, Abdelly C (2007). Effect of sodium chloride on the response of the halophyte species Sesuvium portulacastrum grown in mannitol-induced water stress. Journal of Plant Research 120(2):291-299. https://doi.org/10.1007/s10265-006-0056-X

Sobczak M, Skoczowski A, Oliwa J, Kononowicz AK (2020). Complexity of Brassica oleracea - Alternaria brassicicola susceptible interaction reveals downregulation of photosynthesis at ultrastructural, transcriptional, and physiological levels. Cells 9(10):2329.

Sogoni A, Jimoh M, Kambizi L, Laubscher C (2021). The impact of salt stress on plant growth, mineral composition, and antioxidant activity in Tetragonia decumbens Mill.: An underutilized edible halophyte in South Africa. Horticulturae 7(6):140. https://doi.org/10.3390/horticulturae7060140

Somma S, Amatulli MT, Masiello M, Moretti A, Logrieco AF (2019). Alternaria species associated to wheat black point identified through a multilocus sequence approach. International Journal of Food Microbiology 293:34-43. https://doi.org/10.1016/j.ijfoodmicro.2019.01.001

Vloutoglou I, Fitt BDL, Lucas JA (1996). Germination of Alternaria linicola conidia on linseed: Effects of temperature, incubation time, leaf wetness and light regime. Plant Pathology 45(3):529-539. https://doi.org/10.1046/j.13653059.1996.d01-2.x 
Wided M, Nader BA, Debez A, Kamel H, Riadh K, Chedly A (2009). Physiological and biochemical traits involved in the genotypic variability to salt tolerance of Tunisian Cakile maritima. African Journal of Ecology 47(4):774-783. https://doi.org/10.1111/j.1365-2028.2009.01073.x

Yang ZX, Yang YF, Yu SZ, Wang RG, Wang Y, Chen HL (2018). Photosynthetic, photochemical and osmotic regulation changes in tobacco resistant and susceptible to Alternaria alternata.Tropical Plant Pathology 43(5):413-421. https://doi.org/10.1007/s40858-018-0222-4

Zarrouk M, El Almi H, Ben Youssef, Sleimi N, Smaoui A, Ben Miled, Abdelly C (2003) Lipid composition of local halophytes seeds: Cakile maritima, Zygophyllum album and Crithmum maritimum. In: Crash Crop Halophytes: Recent Studies. 10 Years After the Al Ain (Ed. H. Lieth). Klumer Academic Publishers Group, Dordrecht.

Zribi OT, Labidi N, Slama I, Debez A, Ksouri R, Rabhi M, Smaoui A, Abdelly C (2012). Alleviation of phosphorus deficiency stress by moderate salinity in the halophyte Hordeum maritimum L. Plant Growth Regulation 66(1):75-85. https://doi.org/10.1007/s10725-011-9631-9

Xu ZZ, Zhou GS, Han G, Li Y (2011). Photosynthetic potential and its association with lipid peroxidation in response to high temperature at different leaf ages in maize. Journal of Plant Growth Regulation 30:41-50. https://doi.org/10.1007/s00344-010-9167-7

Xu ZZ, Zhou GS, Shimizu H (2009). Effects of soil drought with nocturnal warming on leaf stomatal traits and mesophyll cell ultrastructure of a perennial grass. Crop Science 49:1843-1851. https://doi.org/10.2135/cropsci2008.12.0725
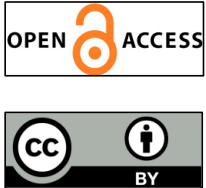

The journal offers free, immediate, and unrestricted access to peer-reviewed research and scholarly work. Users are allowed to read, download, copy, distribute, print, search, or link to the full texts of the articles, or use them for any other lawful purpose, without asking prior permission from the publisher or the author.

License - Articles published in Notulae Botanicae Horti Agrobotanici Cluj-Napoca are Open-Access, distributed under the terms and conditions of the Creative Commons Attribution (CC BY 4.0) License. (c) Articles by the authors; UASVM, Cluj-Napoca, Romania. The journal allows the author(s) to hold the copyright/to retain publishing rights without restriction. 